\title{
Perceptual selectivity and information processing by fast and slow learners in paired-associate learning
}

RONALD J. PARSONS 1

MISSOURI VALLEY COLLEGE

\begin{abstract}
Utilizing a design requiring perceptual rather than verbal discrimination in a compound-stimulus, P-A learning task, two hypotheses related to individual differences in perceptual selection of a functional stimulus cue and the processing of information were explored. The hypothesis that fast learners (determined by pretest) would "process" more information than slow learners in $P-A$ learning was supported. Slow learners consistently ignored the random shape to which instructions specifically directed them and selected instead the context color as the functional cue. A second hypothesis that negative transfer due to proactive inhibition would be greater for slow learners was also supported.
\end{abstract}

The typical paired-associate task requires the $S$ to associate some combination of verbal stimulus and response. Rather than follow this time-honored model, the present experiment explored patterns of cue selection when the stimulus member necessitated visual instead of verbal recognition. The primary purpose was to investigate perceptual selectivity by fast as contrasted with slow learners when a compound non-verbal stimulus was presented.

The experiment consisted of two parts. In the first the I. V. was the rate of learning as determined by a P-A pretest, and the D. V. was the amount of information "processed" by the $S$ as the pairs were learned. In the second part the I. V. was whether the context color of the stimulus created positive transfer or interference in a second learning task, and the $\mathrm{D}$. V. was the rate of learning the second P-A list.

The design of this experiment introduces a dimension differing rather sharply from the majority of P-A studies, namely the use of random shapes as the primary stimulus member. Researchers in visual perception have developed (Attneave \& Arnoult, 1956) and have systematized (Vanderplas \& Garvin, 1959) random shapes to provide a nonrepresentative stimulus, analogous to the nonsense syllable so widely used in verbal learning, having structure not readily identifiable from prior associates. While associations to random shapes can be obtained, Ss appear not to have consistent pre-established associations.

The "borrowing" of the figures for use in a learning study occurred as a result of growing recognition that nonsense syllables frequently fail to provide the meaningless stimulus intended. Underwood (1966), and others, have noted that S may use only the initial letter of the nonsense syllable, ignoring the rest, thus subverting the intended function of the nonsense syllables. The present study has attempted to minimize the S's use of previously established cues by using random figures rather than verbal stimuli.

A theoretical model which has proven suggestive for the design and analysis of this research has been the information processing model. The concepts developed by information theorists have provided a number of relevant clues as to the manner in which the storing and processing of information by the central nervous system may be represented. Of particular concern is the mode of programming input data by the individual. Underwood (1963) has pointed out that what the human $S$ does with the data (stimulus) is often determined by the instructional set introduced by the $\mathrm{E}$, or that the $\mathrm{S}$ may impose his own pattern of selecting a functional stimulus.

P-A learning, per se, imposes a particular "program" on the learner, in contrast to, for example, serial learning. The information processing approach suggests that discrete learning programs are initiated by variations in input instructions, including the condition of presentation. The present research problem, stated earlier, relates most directly to the theoretical model in the analysis of the amount of information "processed" by the learner, and also in the concept of selective perception of input (the cue used) when a compound stimulus is available. Several studies investigating cue selection in P-A learning have been conducted (Weiss \& Margolius, 1954; Sundland \& Wickens, 1962; Underwood et al, 1962; Young et al, 1966). Self-selection of the functional cue is consistently indicated, and the more meaningful element of a compound stimulus has been shown to become the functional cue. That individual differences exist in rate of learning is axiomatic; an implicit assumption, however, appears to have been that the process of perceptual selection is essentially identical for all Ss. The present study hypothesized that identifiable individual differences in cue selection could be isolated. This approach developed out of a recent pilot study comparing patterns of stimulus cue selection using geometric figures, in either a random or recognizable pattern, and having a context color. It was found that rate of learning when the primary stimulus was a recognizable shape was no more rapid than with the meaningless random shape; Ss did, however, utilize the contextual (color) cue to a much greater extent with the nonmeaningful figure. Some serendipidous findings of this study, moreover, indicated that Ss who were learning the P-As most rapidly (with either the meaningful or nonmeaningful stimulus figures) were using the context color very little as an aid in forming the associations. The possibility of an inverse relationship between rate of learning and the use of contextual cues was thus suggested.

\section{Subjects}

\section{METHOD}

The Ss were 20 undergraduate students in an introductory psychology course, selected from 70 in the class to whom were administered a pretest to determine rate of P-A learning.

\section{Apparatus and Materials}

The materials used were presented manually on $5 \times 18$ in. cards. One half of the card contained the stimulus figure, cut out of black construction paper and mounted on a colored background. The other half contained the response, a nonsense syllable taken from the Glaze (1928) list of $20 \%$ association value, and printed in black on the white background. Seven cards were prepared with "nonmeaningful" figures, consisting of 12-sided random shapes, selected and pretested for a high degree of dissimilarity. Two sets of seven "meaningful" figures were prepared, paired with the same seven nonsense syllables used with the nonmeaningful figures. One set of seven meaningful stimulus figures (to be used for positive transfer) was mounted on the same colored backgrounds as the random shapes. The other set (for negative transfer or interference) was mounted so that a different color was paired with the CVC than was the case for the random shapes. Characteristics of the $S$ and $R$ materials are shown in Table 1. Cards were also prepared to enable the meaningful figures, or the nonmeaningful figures, or the colors to be presented independently.

The apparatus used to present the P-A cards consisted of a $4 \times 3$ ft Masonite screen, mounted to stand vertically. Two $5 \times 8$ in. apertures were cut in the center, separated by a narrow dividing strip. The response side was fitted with a sliding shutter, controlled by E. A small lamp was attached to the frame to provide a constant level of illumination on the cards. Data sheets for each $S$ were used to record S's responses during the acquisition and recall trials. The apparatus was set up so that after giving instructions $\mathrm{E}$ was not seen by $\mathrm{S}$ during the experiment.

\section{Procedure}

A P-A pretest consisting of 10 pairs of $40 \%$ association value nonsense syllables (with no color context used) was administered to 70 undergraduate students in an introductory psychology 
Table 1

Meaningful S and R Materiats*

\begin{tabular}{|c|c|c|c|c|}
\hline \multicolumn{2}{|c|}{ Stimulus (Positive Transfer) } & \multirow{2}{*}{$\begin{array}{l}\text { Response } \\
\begin{array}{l}\text { Nonsense } \\
\text { syllable }\end{array}\end{array}$} & \multicolumn{2}{|c|}{ Stimulus (Negative Transfer) } \\
\hline Color & Shape & & Color & Shape \\
\hline Red & Triangle & C I W & Brown & T riangle \\
\hline Orange & Star & YOJ & Green & Star \\
\hline Yellow & Cross & M E Z & Red & Cross \\
\hline Blue & Square & Q A M & Yellow & Square \\
\hline Groen & Crescent & B E H & Pink & Crescent \\
\hline Pink & Circle & $Z \mathbf{I D}$ & Orange & Circle \\
\hline Brown & Diamond & G U H & Blue & Diamond \\
\hline
\end{tabular}

Nonmeaningful cands were identical to the positive transfer cards with the exception of having the 12-sided shapes rather than the recognizable figure.

course. The 10 pairs were shown three times for study, then the stimulus members alone were shown and the students were asked to write the response on numbered sheets which had been distributed to them. From this group of 70 the 10 students with the highest number of correct responses were selected as the fast learning group, and the 10 students with the fewest correct responses were selected as the slow learning group. The mean number of correct responses for the fast group was 7.7; the mean for the slow group was 1.1 correct responses. 2 The 20 students chosen were not informed as to the basis for their being selected to participate in the experiment. Each of the Ss was tested individually in a small laboratory.

Each $S$ participated in both of two conditions. Condition $A$ consisted of learning the seven pairs with the nonmeaningful stimulus, the criterion being one errorless trial. Each $S$ was then tested for recall, first having three trials with the random shapes alone, then three trials with the context colors alone. The amount of information processed in the learning was measured by the total score of the six recall trials.

Each $S$ was seated about $6 \mathrm{ft}$ from the apparatus. $E$ read verbatim the following instructions:

This is an experiment in paired-associate learning. $A$ black figure on a colored background will appear in the left opening. $A$ three-letter nonsense syllable will be seen in the right opening. Your task is to associate the black figure with the nonsense syllable when only the figure appears. There are seven pairs to learn. On the first trial you will be shown both halves of the seven pairs. Then on the following trials the black figure will be shown for 3 sec before the nonsense syllable appears. Try to anticipate the nonsense syllable and spell it aloud before it appears. We want to find out how many trials are required before you can remember all seven nonsense syllables in response to the black figures.

The stimulus and then the S-R pairs were presented at a 3:3-sec rate with a $6 \mathrm{sec}$ interpair interval and a $30 \mathrm{sec}$ intertrial interval. Between each trial the order of the cards was randomly rearranged to prevent serial learning.

Condition B was a test of transfer effects, either positive or negative. In Task B-1 (positive transfer) the response was identical to Task $A$, and the context color of the stimulus was also unchanged. The primary stimulus was a recognizable figure, as listed in Table 1. In Task B-2 (interference) the response was again unchanged, but the context color was rearranged from that used in Task A. (For example, in Task A, the blue context color, plus a random figure, was paired with QAM. In Task B-1 the blue context color, plus a square figure, was paired again with QAM. In Task B-2, however, the context color was yellow, with the square, and paired with QAM, thus providing a negative transfer from the previous learning.)

\section{Hypotheses}

The experiment was designed to test two hypotheses, derived from theoretical assumptions and from related research. These were: (1) The fast learners would not only learn Task A with fewer trials, but would show a tèndency to "process" a greater amount of information in doing so. (2) Greater interference would be found for the slow learners, while positive transfer would show little difference between the two groups.

\section{RESULTS AND DISCUSSION}

As expected, the number of trials to reach criterion on Task $A$ showed marked differences between the two groups. The mean number of trials to criterion for the fast-learner group was 6.3, while for the slow-learner group a mean of 13.4 trials was required, a difference significant at well beyond .01 .

The test of the total amount of information processed in the learning (i.e., the sum of the figure-recall trials plus the color-recall trials) revealed that the fast-learner group did retain a greater amount of information. The mean number of correct responses for the fast group was 27.1 (out of a possible 42). The mean for the slow group was 18.4 correct responses. The difference between these two means is significant beyond $.01 \quad(t=8.5, \mathrm{df}=18)$. Hypothesis 1, as stated earlier, is thus supported. Data such as these suggest that the processing of greater amounts of available information by the fast group may be a partial explanation of why they are fast learners.

When, however, the responses of the two groups are broken down according to the number of correct responses to the figure alone and the color alone, some interesting comparisons appear. While the fast group had a significantly greater number of total correct responses, the number of responses to the color alone was less than that of the slow group. The slow group made a mean of 15.6 correct responses to color alone, but only 2.8 correct responses to figure alone. The fast group had a mean of 14.4 correct responses to color alone and 12.7 correct responses to figure alone. A summary of the results for Condition $A$ is given in Table 2.

These data indicate that while the fast learners, for the most part following the instructions given them by $\mathrm{E}$, were able to learn the pairs using the figures, the slow learners quickly shifted to the use of the color as the functional stimulus cue, with many of them almost totally ignoring the figure. It might be said that they "programmed" their own input contrary to the instructions given them.

Analysis of these data point to a further cogent interpretation of the group differences in perceptual selectivity of the input data. The ability of the one group to integrate new data toward which a set was initiated by the instructions (the random shapes), contrasted with the reliance of the other group on previously integrated cues (color), suggests differences in the two groups other than simply the ability to process more information.

The second hypothesis predicted that the slow learning group would manifest greater negative transfer effect, due to the context color interference, than was seen for the fast learning group. The hypothesis further suggested that little difference would be seen between the two groups in positive transfer, produced by color identity for Conditions A and B.

Since testing each $S$ for both positive and negative transfer did not appear feasible, the two groups were divided. Five Ss from the 
Table 2

Mean Number of Trials and Number of Correct Recall Responses

\begin{tabular}{ccccc}
\hline & $\begin{array}{c}\text { Trials to } \\
\text { Criterion }\end{array}$ & $\begin{array}{l}\text { Responses } \\
\text { (Fig. only) }\end{array}$ & $\begin{array}{l}\text { Responses } \\
\text { (Color only) }\end{array}$ & $\begin{array}{l}\text { Total } \\
\text { Responses }\end{array}$ \\
\hline $\begin{array}{c}\text { Group 1 } \\
\text { (Fast learners) }\end{array}$ & 6.3 & 12.7 & 14.4 & 27.1 \\
\hline $\begin{array}{c}\text { Group 2 } \\
\text { (Slow learners) }\end{array}$ & 13.4 & 2.8 & 15.6 & 18.4 \\
\hline
\end{tabular}

fast group and five from the slow group were run under positive transfer effect, with an equal number having negative transfer effects. To lessen the effect of within-group $S$ differences, each $S$ in the positive transfer group was matched with a $S$ in the negative group having a similar number of trials on Task $A$. In the fast group the five positive transfer Ss had a mean of 6.6 trials to criterion and the negative transfer Ss had a mean of 6.0 trials. In the slow group the positive transfer Ss had a mean of 13.8 trials to criterion on Task A while the negative transfer Ss had 13.0 trials.

The results of Condition B trials provide clear support for the second hypothesis. The five Ss from the fast group having positive transfer trials require a mean of 1.2 trials to criterion. (Criterion, as in Condition A, was one errorless trial.) The five Ss from the slow group having positive transfer needed a mean of 1.6 trials to criterion. The difference is not significant.

The data for the negative transfer effect also support the hypothesis. The five fast group Ss needed a mean of only 3.2 trials under negative transfer conditions while the slow group required a mean of 10.6 trials to criterion. The difference is clearly significant and indicates that $S s$ in the slow group were, as hypothesized, more subject to interference produced by the influence of color incongruity in the two learning tasks than was the fast group. Data for both positive and negative transfer groups are summarized in Table 3.

As Table 3 indicates, $S s$ in Condition B were also tested for recall, using the recognizable figure alone as the stimulus. These data show that while the slow-positive Ss were able to reach criterion nearly as fast as the fast-positive group, their performance on the recall trials was grossly inferior. This difference in figure-recall of 17.6 vs 4.8 is particularly significant in view of the fact-quickly apparent to both groups-that attention to the primary stimulus figure (recognizable shape) was unnecessary for producing the correct responses. The conclusion indicated is that, as in Condition A, the slow group was relying heavily on the color as the stimulus cue, while the fast group, though aided by the color, was also rapidly processing information which enabled them to make a very high number of correct recall responses. (The mean of 17.6 was out of a possible 21.)

The slow-negative group, forced to discard their previously integrated color cues, produced a much higher number of correct recall responses to the figure stimulus (mean $=15.0$ ), but still performed at a rate inferior to the fast-negative group (mean = 18.6).

An additional possible interpretation-ancillary to the previously considered possibility of a subject-variable in information-

Table 3

Effect of Positive and Negative Transfer

\begin{tabular}{|c|c|c|c|}
\hline & & $\begin{array}{l}\text { Trials to } \\
\text { Criterion }\end{array}$ & $\begin{array}{l}\text { Recall } \\
\text { (Fig. only)* }\end{array}$ \\
\hline \multirow{2}{*}{$\begin{array}{l}\text { Positive } \\
\text { transfer }\end{array}$} & Fast group & 1.2 & 17.6 \\
\hline & Slow group & 1.6 & 4.8 \\
\hline \multirow{2}{*}{$\begin{array}{l}\text { Negative } \\
\text { transfer }\end{array}$} & Fast group & 3.2 & 18.6 \\
\hline & Slow group & 10.6 & 15.0 \\
\hline
\end{tabular}

*Ss were not tested for recall with color in Condition B. Having been tested for color-recall only a few minutes earlier, to do so again would have been largely redundant. processing capacity-may be suggested to account for the superior recall performance of the fast group for both random and recognizable figures. This is the degree to which Ss attend to the instructions given by $\mathrm{E}$. The fast group appears to demonstrate a greater ability, or inclination, to attend to instructions given in this study of a perceptual and learning situation. The slow group Ss, finding the random-shape stimulus figures essentially meaningless for the task of readily forming associations, engaged in a process of "self-programming" and used instead the context color, selecting as input data the more immediately meaningful, and therefore more readily integrated, stimuli, even though this went counter to the instructions given them.

\section{SUMMARY}

An experiment exploring patterns of cue selection by fast and by slow learners in a P-A task, and also investigating the positive and negative transfer effect in a second learning task was conducted with 10 fast and 10 slow learners, as measured by a P-A pretest. A design was utilized which required perceptual rather than verbal discrimination of the stimulus cue. The hypothesis that fast learners would not only require fewer trials to criterion but would also process more information was supported. A second hypothesis that the slow-group Ss would show greater interference due to negative transfer, but that positive transfer differences would be insignificant was also supported. Both positive-transfer groups required a nearly equivalent number of trials to criterion; figure-recall by the fast group, however, was significantly superior.

\section{REFERENCES}

ATTNEAVE, F., \& ARNOULT, M. D. The quantitative study of shape and pattern recognition. Psychol. Bull., 1956, 53, 452-471.

GLAZE, J. A. The association value of non-sense syllables. J. genet. Psychol., $1928,35,255-269$.

MANDLER, G. Verbal learning. In T. Newcomb (Ed.), New directions in psychology, III. New York: Holt, Rinehart, Winston, 1967.

OSGOOD, C. E. Meaningful similarity and interference in learning. J. exp. Psychol, 1946, 36, 277-301.

SAUFLEY, W. H., JR., \& UNDERWOOD, B. J. Cue-selection interference in paired-associate learning. J. verbal learn. verbal Behav., 1964, 3, 474479.

SUNDLAND, D. M., \& WICKENS, D. D. Context factors in paired-associate learning and recall. J. exp. Psychol, 1962, 63, 302-306.

UNDERWOOD, B. J. Experimental psychology. New York: AppletonCentury-Crofts, 1966.

UNDERWOOD, B. J., HAM, M., \& EKSTRAND, B. Cue-selection in paired-associate learning.J. exp. Psychol, 1962, 64, 405-409.

VANDERPLAS, J. M., \& GARVIN, E. A. The association value of random shapes. J. exp. Psychol, 1959a, 57, 147-154.

VANDERPLAS, J. M., \& GARVIN, E. A. Complexity, association value, and practice as factors in shape recognition following paired-associates training. J. exp. Psychol, 1959b, 57, 155-163.

WEISS, W., \& MARGOLIUS, G. The effect of context stimuli on learning and retention. J. exp. Psychol, 1954, 48, 318-322.

YOUNG, R. I., MARROW, J., SEITZ, S., \& HAYS, M. Backward recall with compound stimuli. J. exp. PsychoL, 1966, 72, 241-243.

\section{NOTES}

1. Address: Department of Psychology, Missouri Valley College, Marshall, Missouri 65340.

2. References here and following to "fast group" or "slow group" refer to rate of P-A learning as measured by the pretest, and may or may not be indicative of differences in other forms of learning. 